RAIRO-Oper. Res. 55 (2021) 899-919

https://doi.org/10.1051/ro/2021045

RAIRO Operations Research

www.rairo-ro.org

\title{
MULTI-OBJECTIVE OPTIMIZATION BASED OPTIMAL SIZING \& PLACEMENT OF MULTIPLE DISTRIBUTED GENERATORS FOR DISTRIBUTION NETWORK PERFORMANCE IMPROVEMENT
}

\author{
Anilkumar Markana*, Gargi Trivedi and Praghnesh Bhatt
}

\begin{abstract}
Integration of Distributed Generations (DGs) into radial distribution network (RDN) is an emerging need to explore the benefits of renewable energy sources (RES). Increasing penetration of RES based DGs in RDN without proper planning leads to several operational problems such as excessive energy losses, poor voltage quality and load balancing. Hence, in this work, multi-objective optimization (MOO) problem is formulated by carefully chosen three conflicting objectives such as power loss minimization, enhancement of load balancing index (LBI) and aggregate voltage deviation index (AVDI). Teaching-Learning-Based-Optimization (TLBO) is used to optimize MOO problem considering placement of DGs at multiple locations in RDN satisfying the constraints on bus voltage magnitude, branch flows and DG size. Comprehensive simulation studies have been carried out to obtain optimal performance for 69-nodes RDN with the increasing penetration of DGs at multiple locations. It is shown that determination of optimal sizing of DGs at multiple locations in RDN with MOO results in lesser power losses, improved voltage profiles and better load balancing as compared to placement of single DG in RDN. Performance measures such as spacing and spread indicators are used for characterizing Pareto solutions for MOO problem. Such set of non-dominated solutions obtained from Pareto front during multi-objective TLBO gives proper guidelines to the utility operator about sizing and placement of DGs based on the assigned priorities to the objectives.
\end{abstract}

Mathematics Subject Classification. 90C29.

Received December 30, 2019. Accepted March 21, 2021.

\section{INTRODUCTION}

DGs are small generating units connected directly to the distribution network at the customer nodes. DG is also known as decentralized generation, dispersed generation, or embedded generation. The proper placement and sizing of DGs in distribution network can improve the voltage profiles, reduce active and reactive power losses, enhance voltage stability and power quality. However, sub-optimal DG placement adversely impacts the operation of the distribution network, thus it may result in increased system losses, more voltage violation and increased network operating costs. Therefore, optimal DG placement and sizing problem has attracted attention of many researchers in the last decade [2,8]. The conventional methods such as Gauss-Seidel (GS) and NewtonRaphson (NR) are not suitable for the power flow solution of RDN as GS method fails to converge for higher $R / X$

Keywords. Multi-objective optimization, TLBO, distributed generations, radial distribution network.

Department of Electrical Engineering, Pandit Deendayal Petroleum University, Gandhinagar, India.

*Corresponding author: anil.markana@gmail.com 
ratio of RDN whereas NR occupies generally larger computational efforts. Hence, for RDN, Forward/Backward Sweep (FBS) based method is more popular for power flow analysis of distribution network [25, 27]. Placement and sizing of DGs in RDN is a complex optimization problem and requires to consider multiple objectives to be solved simultaneously [16]. There are physical constraints in terms of capacity and sizing of DGs, thermal limits consideration of line and voltage limit at the nodes [15]. An analytical approach based on exact loss formula is presented in [1] for finding optimal size of DG and its optimal location in distribution network. This method is limited to identify only a single DG location of optimal size.

Impact of optimal placement of different DG types on power losses, voltage profile and voltage stability of RDN has been reported in [17] for 33-nodes RDN considering only one DG placement at a time. Techno-economic analysis of optimal placement of multiple DGs in RDN has been studied in [18] considering future load growth up to five years. The single-objective optimization problem is formulated to minimize only active power losses using particle swarm optimization with constriction factor approach (PSOCFA). Optimal sizing and siting of DG has been ascertained in [22] using intelligent water drop (IWD) algorithm using single-objective function for minimization of total line loses based on loss sensitivity factor (LSF).

Backtracking search algorithm (BSA) is used in [12] to find out optimal location of DG with consideration of active power loss minimization considering different load models. The authors in [13] have used BSA for optimal allocation of multi-type DGs in RDN considering multi-objective optimization problem. Active power loss minimization and voltage stability maximization are selected to formulate multi-objective optimization problem and proposed solution was limited to determine optimal type of DG sources at maximum two optimal locations.

The multi-objective optimization considering active power losses, the total emission produced and the total cost related to the grid \& DGs for optimal placement of single DG is reported in [4] utilizing an interactive fuzzy approach based on improved particle swarm optimization (IPSO). The reconfiguration of the distribution network in the presence of distributed generations based on active power loss minimization is addressed in [9]. Multi-Objective Particle Swarm Optimization (MOPSO) algorithm combined with Taxi-cab method, was proposed in [21] to find optimal $P$ and $Q$ set-points of soft open points where improvement in voltage profile, minimization of power loss and balancing of feeder load were set as objectives. Reactive power output of multiple DGs has been optimized in [7] with time-series power flow optimization considering two separate objective function such as real power loss minimization and aggregate voltage deviation. Recently, the problem of optimal sizing and location of DG considering loss minimization and voltage stability enhancement have been reported in $[3,11,20]$, using different search algorithms.

Combined genetic algorithm (GA)/particle swarm optimization (PSO) is presented in [19] for optimal placement and sizing of DG in RDN with an objective is to minimize power losses, improve voltage stability and for better voltage regulation. Teaching-Learning-Based Optimization (TLBO), is proposed in [23, 24] for obtaining global solutions for continuous non-linear functions. It takes less computational effort and gives high consistency in finding the optimal solutions. TLBO is based on the influence of a teacher on the output of learners in a class. Authors in $[26,28]$ have applied TLBO for obtaining optimal sizing and location for DGs in RDN. The results obtained from TLBO in [26] are better than GA, PSO and Combined GA/PSO in [19] to ascertain DG sizing and location considering single objective as well multi-objective problems. However, placement for DG in [26] are limited to only three locations in RDN.

Referring to the literature review, it has been critically observed that more attention has been given to determine only single optimal location for DG which satisfy the single objective function of minimization of real power losses. Determination of multiple DG location and its sizing using multi-objective optimization were addressed in literature, but the approaches were limited to determine only two/three/five DG locations. In [18], DGs are optimally placed at multiple location, but optimization problem was limited to only single objective function of real power loss minimization. The objectives of distribution network operator (DNO) are to minimize power losses, to reduce node voltage deviation and to enhance load balancing index even with the highest penetration level of DGs on DN. Placement of DGs at multiple locations is the only way of increasing penetration level of DGs. Thus, it is significantly important to analyze the performance of DN considering the 
placement of DG at almost all buses of DN and optimizing the problem which satisfy the different objectives of DNO all together. Hence, in this work, the efforts are made for finding the optimum location and sizing of multiple DGs at different nodes of RDN by formulating multi-objective optimization problem with three different objectives such as power loss minimization, improvement in voltage profile and load balancing index.

The paper is organized as follows. Section 2 describes the mathematical formulation for power flow solution in Distribution Network. Introduction to MOO is briefly presented in Section 3. Multiple conflicting objectives in Distribution Network are defined in Section 4. Formulation of TLBO algorithm is discussed in Section 5. The simulation studies and results for placement and sizing of multiple DGs in RDN are presented in Section 6, followed by conclusions and future directions in Section 7 .

\section{MAThematical FORMUlation FOR POWER FLOW SOLUTION IN DistRibUtion NETWORK}

The distribution networks (DN) are generally radial in nature and possess high $\frac{R}{X}$ ratio. Hence, traditional power flow methods such as Newton-Raphson (NR) and fast decoupled power flow (FDPF) sometimes fail to converge for DN due to it's ill-conditioned characteristics. The power flow solution for distribution network has also an impact on other important applications such as network optimization, reconfiguration, reactive power planning and DG placements. Bus injection to branch current matrix (BIBC) and the branch current to bus voltage matrix (BCBV) based methods are proposed in [27] to obtain the better power flow problem solutions in DN.

\subsection{Formulation of BIBC and BCBV matrix}

BIBC and BCBV matrices are dependent on topological structure of distribution systems. The BIBC matrix captures the relationship between bus current injections and branch currents. Changes in active and reactive power loads at any bus cause change in corresponding bus current which is immediately reflected in branch currents connected at that bus. Thus, BIBC effectively captures the changes in loading conditions. The BCBV matrix represents the relationship between branch currents and bus voltages.

For node $p$, the complex power is given by

$$
S_{p}=\left(P_{p}+j Q_{p}\right)
$$

where,

$$
p=1,2, \ldots, N_{B}
$$

$P_{p}$ and $Q_{p}$ are active and reactive power available at node $p$ and $N_{B}$ is total number of nodes in DN. During iteration $k$, equivalent current injection at node $p$ is given by

$$
I_{p}^{k}=I_{p}^{r e}+j I_{p}^{i m}=\left(\frac{P_{p}+j Q_{p}}{V_{p}^{k}}\right)^{*}
$$

where, $I_{p}^{k}$ and $V_{p}^{k}$ are the equivalent current injection and voltage at node $p$ during $k$ th iteration, respectively. $I_{p}^{r e}$ and $I_{p}^{i m}$ are real and imaginary components of equivalent current injection at node $p$ during $k$ th iteration, respectively.

Consider a simple radial distribution network as shown in Figure 1. Generally, active and reactive power injection at node $p$ are defined. The equivalent current injections at node $p$ can be obtained through these defined power injections using equation (2.1). Kirchhoff's Current Law (KCL) is then used to obtain the relationship between the bus current injections and branch currents. 


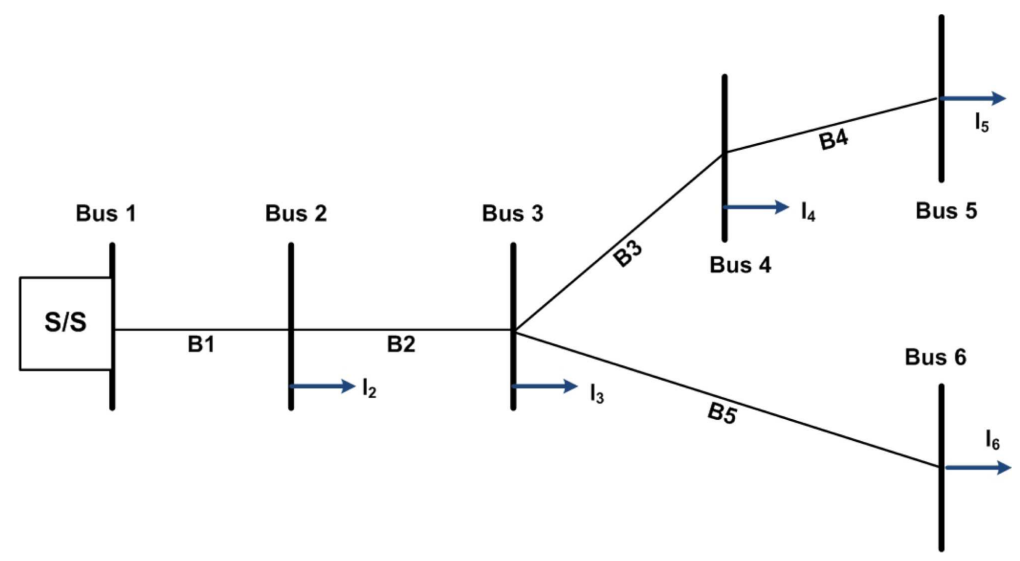

FiguRE 1. Sample radial distribution network.

Referring to Figure 1, branch current $B_{l}$, for $l=1$ to $N_{\text {Branch }}$ can be expressed by equivalent current injections as

$$
\begin{aligned}
& B_{1}=I_{2}+I_{3}+I_{4}+I_{5}+I_{6} \\
& B_{3}=I_{4}+I_{5} \\
& B_{5}=I_{6} .
\end{aligned}
$$

Thus, relationship between bus current injections and branch currents can be expressed as equation (2.6) which can be represented in generalized form as given in equation (2.7)

$$
\begin{gathered}
{\left[\begin{array}{l}
B_{1} \\
B_{2} \\
B_{3} \\
B_{4} \\
B_{5}
\end{array}\right]=\left[\begin{array}{lllll}
1 & 1 & 1 & 1 & 1 \\
0 & 1 & 1 & 1 & 1 \\
0 & 0 & 1 & 1 & 0 \\
0 & 0 & 0 & 1 & 0 \\
0 & 0 & 0 & 0 & 1
\end{array}\right]\left[\begin{array}{l}
I_{2} \\
I_{3} \\
I_{4} \\
I_{5} \\
I_{6}
\end{array}\right]} \\
{[B]=[\mathrm{BIBC}][I]}
\end{gathered}
$$

where, BIBC is the bus-injection to branch-current (BIBC) matrix. Similarly, relation between branch currents and bus voltages for system shown in Figure 1 is established in equation (2.6), where $Z_{p q}$ is the branch impedance connected between bus $p \& q$ and $V_{p}$ is the voltage at bus $p$.

$$
\begin{aligned}
& V_{2}=V_{1}-B_{1} Z_{12} \\
& V_{3}=V_{2}-B_{2} Z_{23} \\
& V_{4}=V_{3}-B_{3} Z_{34} .
\end{aligned}
$$

Individual bus voltage at bus 4 , in equation (2.9), can be represented in terms of branch current, line impedance and substation voltage $\left(V_{1}\right)$ using equation $(2.8)$.

Similarly, equation (2.9) can be extended for all other buses in DN and can be represented as generalized matrix equation as $(2.10)$

$$
V_{4}=V_{1}-B_{1} Z_{12}-B_{2} Z_{23}-B_{3} Z_{34}
$$




$$
\left[\begin{array}{l}
V_{1} \\
V_{1} \\
V_{1} \\
V_{1} \\
V_{1}
\end{array}\right]-\left[\begin{array}{l}
V_{2} \\
V_{3} \\
V_{4} \\
V_{5} \\
V_{6}
\end{array}\right]=\left[\begin{array}{ccccc}
Z_{12} & 0 & 0 & 0 & 0 \\
Z_{12} & Z_{23} & 0 & 0 & 0 \\
Z_{12} & Z_{23} & Z_{34} & 0 & 0 \\
Z_{12} & Z_{23} & Z_{34} & Z_{45} & 0 \\
Z_{12} & Z_{23} & 0 & 0 & Z_{36}
\end{array}\right]\left[\begin{array}{c}
B_{1} \\
B_{2} \\
B_{3} \\
B_{4} \\
B_{5}
\end{array}\right] .
$$

Above equation (2.10) can be expressed in generalized form as equation (2.11), where, BCBV is the branchcurrent to bus voltage (BCBV) matrix.

$$
[\Delta V]=[\mathrm{BCBV}][B] .
$$

Use of equation (2.7) in equation (2.11) results in

$$
[\Delta V]=[\mathrm{DLF}][I]
$$

where, $[\mathrm{DLF}]=[\mathrm{BCBV}][\mathrm{BIBC}]$.

Finally, equations given in (2.13) can be solved iteratively to obtain voltage equations at each node in distribution network for given active and reactive power loading conditions. Using these voltage values, active and reactive power losses can be evaluated using Elgerd's "exact loss formula" [14] discussed in next section.

$$
\begin{aligned}
I_{p}^{k}=I_{p}^{r e}+j I_{p}^{i m} & =\left(\frac{P_{p}+j Q_{p}}{V_{p}^{k}}\right)^{*} \\
{\left[\Delta V^{k+1}\right] } & =[\mathrm{DLF}]\left[I^{k}\right] \\
{\left[V^{k+1}\right] } & =\left[V^{k}\right]+\left[\Delta V^{k+1}\right] .
\end{aligned}
$$

\section{Multi-Objective optimization}

A class of optimization that deals with multiple conflicting objectives is called Multi-objective Optimization (MOO). There are numerous applications of such mutually conflicting objectives in process engineering $[5,6]$. Mathematically, the MOO problem can be represented as follows,

$$
\begin{array}{ll}
\underset{\mathbf{u}}{\operatorname{Min}} \operatorname{Max}_{\mathbf{u}} & \mathbf{f}(\mathbf{u})=\left[f_{1}(\mathbf{u}), f_{2}(\mathbf{u}), \ldots, f_{N}(\mathbf{u})\right] \\
\text { s.t. } & \mathbf{g}(\mathbf{u})=0 \\
& \mathbf{h}(\mathbf{u}) \leq 0 \\
& \mathbf{u}^{\text {low }} \leq \mathbf{u} \leq \mathbf{u}^{\text {high }}
\end{array}
$$

where, $\mathbf{f}$ is a vector of $N$ objective functions to be maximized or minimized. A solution $\mathbf{u}$ is a vector of $n$ decision variables: $\mathbf{u}=\left(u_{1}, u_{2}, \ldots, u_{n}\right)$. Here, $\mathbf{g}$ and $\mathbf{h}$ represent the equality and inequality constraints, respectively. The superscripts low and high stand for the lower and upper bounds on the decision variables, respectively.

Contrary to single objective optimization, there is no single global solution for MOO problem [6]. Instead it involves several solutions characterizing the trade offs between various objectives. Such solutions are called the non dominated solutions, of which none can be said to be better than the others with respect to all the objectives. These non dominated solutions are also known as Pareto optimal solutions and represent the Pareto front.

A solution $\mathbf{u}^{*}$ is said to be Pareto optimal if and only if there does not exist another $\mathbf{u} \in \mathbf{U}$, such that $f_{i}(\mathbf{u}) \leq f_{i}\left(\mathbf{u}^{*}\right)$, for all $i=1,2, \ldots, N$ and $f_{j}(\mathbf{u})<f_{j}\left(\mathbf{u}^{*}\right)$ for at least one index $f$. In other words, a solution is Pareto optimal if an objective $f_{i}$ can be reduced at the expense of increasing at least one of the other objectives. In general, there may be many Pareto optimal solutions for a MOO problem. This can be better understood by the Pareto front of a bi-objective optimization problem, where both objectives are to be minimized, as shown in Figure 2. A feasible solution, say A is said to be Pareto optimal (or non-dominated) if there is no other feasible solution, say B, which has better (or same) values for all the individual objectives than the corresponding 


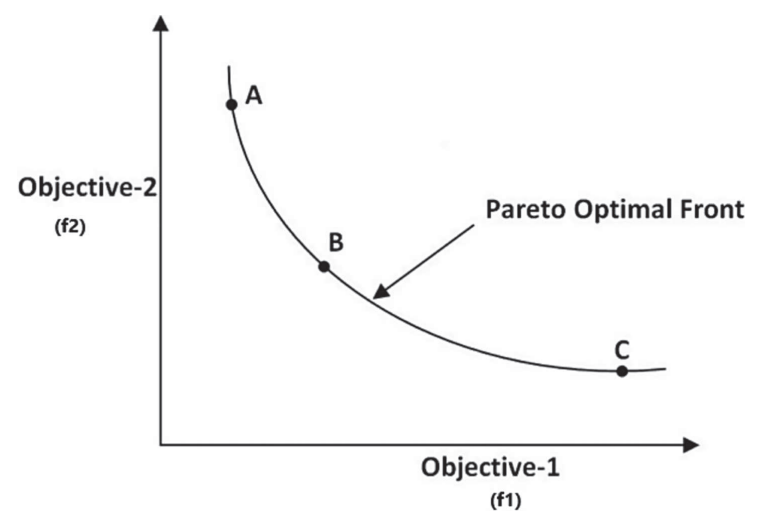

Figure 2. Concept of Pareto optimality considering bi-objective optimization problem.

objectives with solution A. In other words solution A is better than solution B in at least one objective. All the three points $\mathrm{A}, \mathrm{B}$, and $\mathrm{C}$ are the non-dominated solutions and hence make a subset of the Pareto front. On the other hand, solution D is not a Pareto optimal solution, since it is worse than solution B in both the objectives.

\section{MUlti-OBJECTIVES OPtimizATION PROBLEM FOR DISTRIBUTION NETWORK}

In this work, three conflicting objectives namely active power loss minimization, improvement in load balancing index (LBI) and minimization of aggregate voltage deviation index (AVDI) are considered to formulate MOO problem. When DG units penetration increase in DN for minimizing power losses, this would potential restricts DG penetration due to high voltage deviation in the network. On the other hand, a higher penetration of DG units could be achieved when DG units are operated in voltage-controlled mode for minimizing higher voltage deviation alone, but active and reactive power losses could be higher in such cases. Moreover, placements of DG alter the power flow over distribution feeders, which in turn impacts load balancing in distribution feeders. Hence, MOO problem is proposed as per equation (4.1) in order to achieve all three conflicting objectives simultaneously,

$$
\operatorname{Min}(f)=\operatorname{Min}\left(f_{1}, f_{2}, f_{3}\right)
$$

where, $f_{1}, f_{2}$ and $f_{3}$ are three conflicting objectives in MOO problem and are discussed in next subsection.

\subsection{Power loss minimization, $\left(f_{1}\right)$}

Total active and reactive power losses can be calculated using "exact loss formula" [14] in RDN without considering any DG placement as below.

$$
\begin{aligned}
P_{\mathrm{Loss}} & =\sum_{p=1}^{N_{B}} \sum_{q=1}^{N_{B}}\left[a_{p q}\left(P_{p} P_{q}+Q_{p} Q_{q}\right)+b_{p q}\left(Q_{p} P_{q}+P_{p} Q_{q}\right)\right] \\
Q_{\mathrm{Loss}} & =\sum_{p=1}^{N_{B}} \sum_{q=1}^{N_{B}}\left[c_{p q}\left(P_{p} P_{q}+Q_{p} Q_{q}\right)+d_{p q}\left(Q_{p} P_{q}+P_{p} Q_{q}\right)\right]
\end{aligned}
$$


where,

$$
\begin{aligned}
a_{p q} & =\frac{r_{p q}}{V_{p} V_{q}} \cos \left(\delta_{p}-\delta_{q}\right) \\
b_{p q} & =\frac{r_{p q}}{V_{p} V_{q}} \sin \left(\delta_{p}-\delta_{q}\right) \\
c_{p q} & =\frac{x_{p q}}{V_{p} V_{q}} \cos \left(\delta_{p}-\delta_{q}\right) \\
d_{p q} & =\frac{x_{p q}}{V_{p} V_{q}} \sin \left(\delta_{p}-\delta_{q}\right) .
\end{aligned}
$$

$V_{p} \angle \delta_{p}$ is the complex voltage at $p$ th bus. $r_{p q}+j x_{p q}=Z_{p q}$ is the $p q$ th element of impedance matrix [ $\left.Z_{\text {bus }}\right] . P_{p}$ and $P_{q}$ are active power injections at $p$ th and $q$ th buses, respectively. $Q_{p}$ and $Q_{q}$ are reactive power injections at $p$ th and $q$ th buses, respectively.

Placement of DG will impact active and reactive power losses in DN. Here, in this work, DG is modeled at unity power factor, thus it will inject only active power in the network. Therefore, the change in active power injection at $p$ th node with the placement of DG is given as,

$$
P_{p}=P_{\mathrm{DG} p}-P_{D p}
$$

where, $P_{\mathrm{DG} p}$ and $P_{D p}$ are active power generation by DG and active power load demand at $p$ th bus, respectively. With the placement of DG at $p$ th bus with generating active power of $P_{\mathrm{DG} p}$, the real power losses in $\mathrm{RDN}$ is modified as,

$$
P_{\mathrm{Loss} \mathrm{DG}}=\sum_{p=1}^{N_{B}} \sum_{q=1}^{N_{B}}\left[a_{p q}\left(\left(P_{\mathrm{DG} p}-P_{D p}\right) P_{q}+Q_{p} Q_{q}\right)+b_{p q}\left(\left(Q_{p} P_{q}+\left(P_{\mathrm{DG} p}-P_{D p}\right) Q_{q}\right)\right] .\right.
$$

\subsection{Load balancing index, $\left(f_{2}\right)$}

The second objective is to minimize load balancing index (LBI) for improving load balance in the DN. LBI can be calculated as per equation (4.10).

$$
\mathrm{LBI}=\sum_{k=1}^{N_{\text {Branch }}}\left(\frac{I_{k}}{I_{k, \text { rated }}}\right)^{2}
$$

where, $I_{k}$ is the current through $k$ th branch and $I_{k \text {,rated }}$ is the rated current of $k$ th branch.

\subsection{Aggregate voltage deviation index, $\left(f_{3}\right)$}

The third objective is to minimize the aggregate voltage deviation index (AVDI) to improve bus voltage profile. AVDI can be calculated as per equation (4.11). Note that minimizing AVDI will improve the voltage profiles of each bus in the network.

$$
\mathrm{AVDI}=\sum_{i=1}^{N_{B}}\left|V_{i}^{\mathrm{DG}}-V_{\mathrm{ref}}\right|
$$

where, $V_{\text {ref }}$ is nominal node voltage equal to $1 \mathrm{pu}$.

\subsection{Network constraints}

Following network constraints are considered while solving all optimization problems in this work.

All node voltage limits:

$$
V_{p}^{\min } \leq V_{p} \leq V_{p}^{\max } \quad \forall p=1: N_{B}
$$


Sizing limits for DG:

$$
P_{\mathrm{DG}, i}{ }^{\min } \leq P_{\mathrm{DG}_{i}} \leq P_{\mathrm{DG}, i}{ }^{\max } \quad \forall i=1: N_{\mathrm{DG}} .
$$

Branch capacity limits:

$$
I_{k} \leq I_{k, \text { rated }} \quad \forall k=1: N_{\text {Branch }}
$$

\section{TEACHING-LEARNING-BASED-OPTIMIZATION}

Teaching-Learning-Based-Optimization (TLBO) is inspired by the teaching-learning philosophy of any education environment. The TLBO algorithm is proposed by $[23,24]$ based on teaching-learning philosophy of classroom. The algorithm works in two phases namely, (i) learning through teacher and (ii) learning by interacting with the other learners. TLBO is a population based algorithm where population is composed from the group of students (i.e. learner). Further, the different subjects presented to the learners are treated as design variables of the optimization problem. The outcome of a learner in each subject represents a possible solution to the optimization problem. The best solution in the entire population is considered as the teacher.

\subsection{Teacher phase}

In this phase of the algorithm, learners learn through a teacher. The mean result of class depends on the quality of learners. A good teacher tries to uplift the learner's level up to his or her level as far as knowledge is concern. However, strengthening the knowledge of the learners not depends only on the knowledge of the teacher but also depends on the ability of the learners to understand and grasp the knowledge imparted by teacher.

To understand the teacher phase more precisely, assume that $n$ number of learners compose the class (i.e. population size), these learners undergoes $m$ subjects number (i.e. number of design variables) in the class, best learner (best solution) of the class treated as teacher $T$ and mean results of the learner (i.e. population) is $M$. Through teaching-learning process, $T$ will try to move $M$ toward his/her level. Further, mean results of the population is changed depending on the parameter called teaching factor $T_{F}$. Based on the difference between existing and new mean results of the learners solutions is modified as below during the teacher phase,

$$
A_{i, j}^{\text {new }}=A_{i, j}^{\text {old }}+r_{i j}\left(T_{j}-T_{F} M_{j}\right)
$$

where, $i=1,2, \ldots, n$ and $j=1,2, \ldots, m . T_{F}$ is set to either 1 or 2 and decided randomly with equal probability given as

$$
T_{F}=\operatorname{round}[1+\operatorname{rand}(0,1)\{2-1\}]
$$

\subsection{Learner phase}

This phase works based on the knowledge sharing ability between the different learners. Through the mutual discussion with other person (i.e. learner) one can increase his/her knowledge. In that way, any learners improved their knowledge to a better level than existing. Further, the selection of learner follows the random process. Let, two random learners (i.e. solutions) $i$ and $k$ are selected to update solution in this phase as given below,

$$
\text { if }\left(f\left(A_{i}\right)<f\left(A_{k}\right)\right)
$$

$$
A_{i, j}^{\text {new }}=A_{i, j}^{\text {old }}+r_{i j}\left(A_{i, j}^{\text {old }}-A_{k, j}^{\text {old }}\right)
$$

where $(i \neq k)$

else

$$
A_{i, j}^{\text {new }}=A_{i, j}^{\text {old }}+r_{i j}\left(A_{k, j}^{\text {old }}-A_{i, j}^{\text {old }}\right)
$$

where $(i \neq k)$. 
The algorithm works based on above search process till the termination criteria reached. For detailed understanding psudo-code of TLBO algorithm is provided in Algorithm 1.

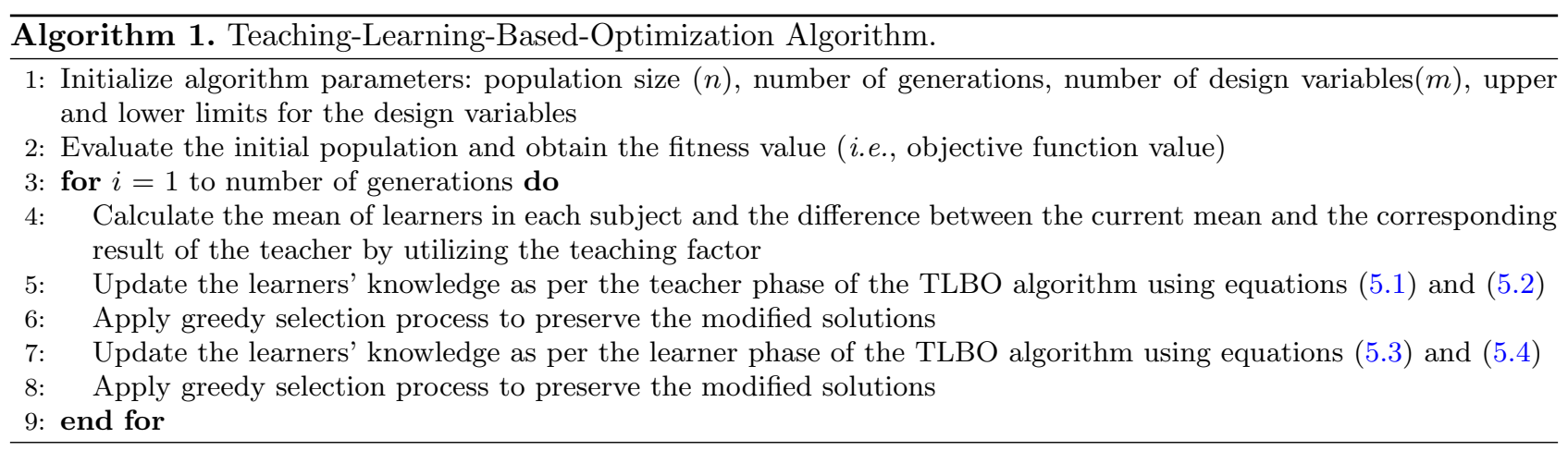

\section{Simulation Studies, Results And Discussions}

Multi-objective optimization is implemented for optimal sizing of DGs at multiple location in 33-nodes and 69-nodes RDN. Active power load demand is 3.72 MW and 3.8 MW for 33-nodes and 69-nodes RDN, respectively whereas reactive power load demand is 2.3 MVAR and 2.69 MVAR, respectively. In base case study without considering any DG placement in 33-nodes and 69-nodes RDN, active power losses equal to $211.20 \mathrm{~kW}$ and $219.28 \mathrm{~kW}$, respectively are obtained through running distribution power flow as discussed in Section 2.

\subsection{Optimal placement of single DG using analytical approach for 33 and 69 bus system}

Finding optimal location for DG placement in order to have minimum losses in the network is the foremost requirement of utility operator. Finding the optimal location for DG with optimal sizing follows Algorithm 2 in analytical approach.

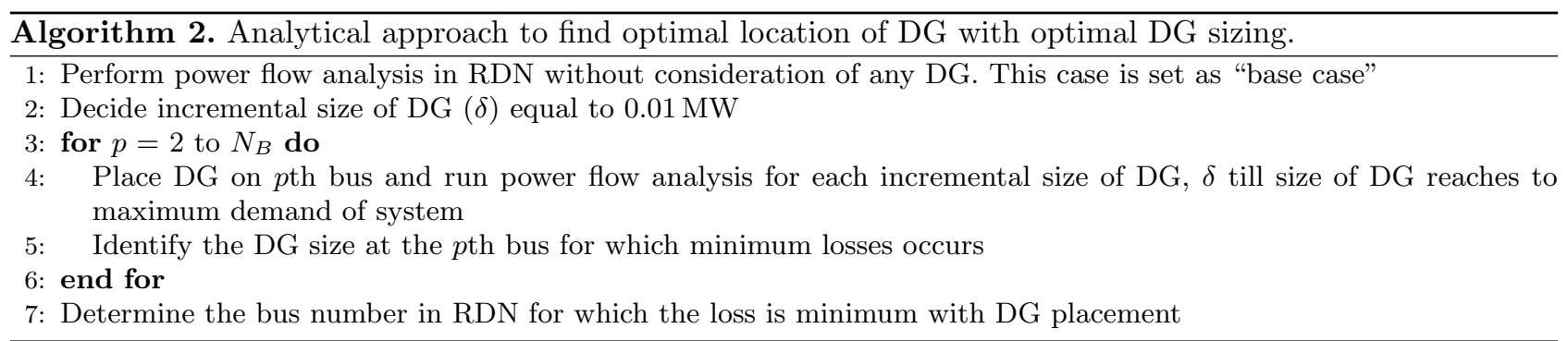

Based on the analytical approach discussed above, optimal location for DG with optimum sizing are determined for 33-nodes and 69-nodes RDN. Optimal size of DG for each bus which has resulted in the minimum losses in 33-nodes and 69-nodes RDN are shown in Figures 3 and 5, respectively. Similarly, the minimum value of losses after the placement of optimal size of DG at each bus in 33-nodes and 69-nodes RDN are shown in Figures 4 and 6 , respectively. It can be clearly noticed that with the placement of $2.49 \mathrm{MW}$ DG (optimal size of DG), in 33 bus RDN, at bus 6, the real power loss has significantly reduced to $111.24 \mathrm{~kW}$ from $211.20 \mathrm{~kW}$. Similarly, with the placement of $1.81 \mathrm{MW}$ DG (optimal size of DG), in 69 bus RDN, at bus 61, the real power 


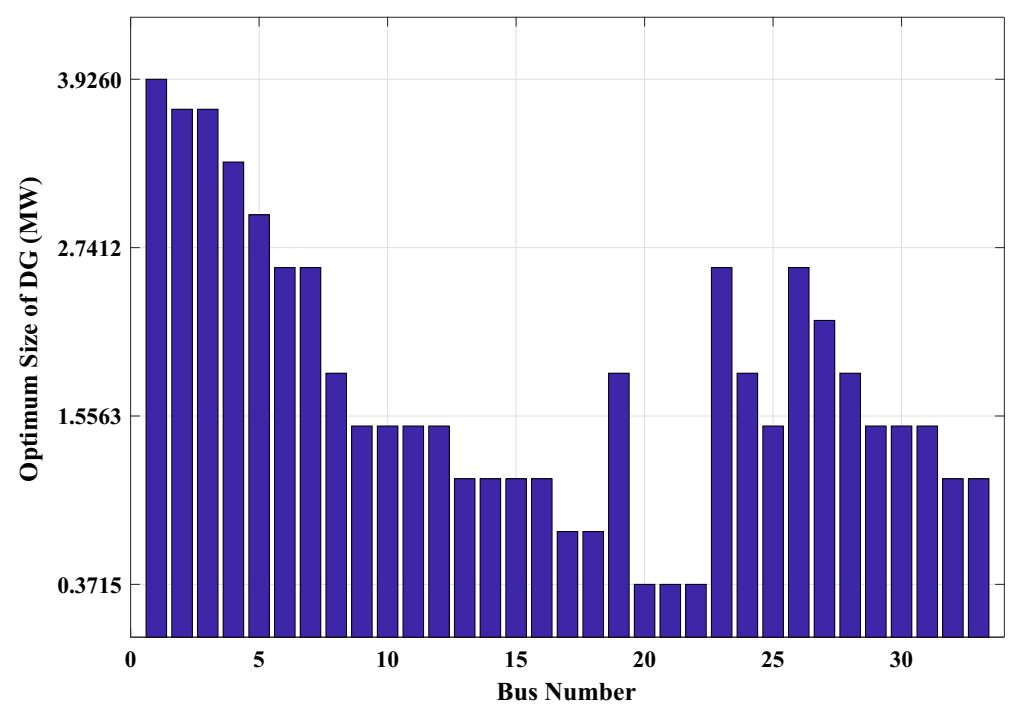

FIGURE 3. Optimal size of DG on individual bus obtained with analytical approach: 33-bus test system.

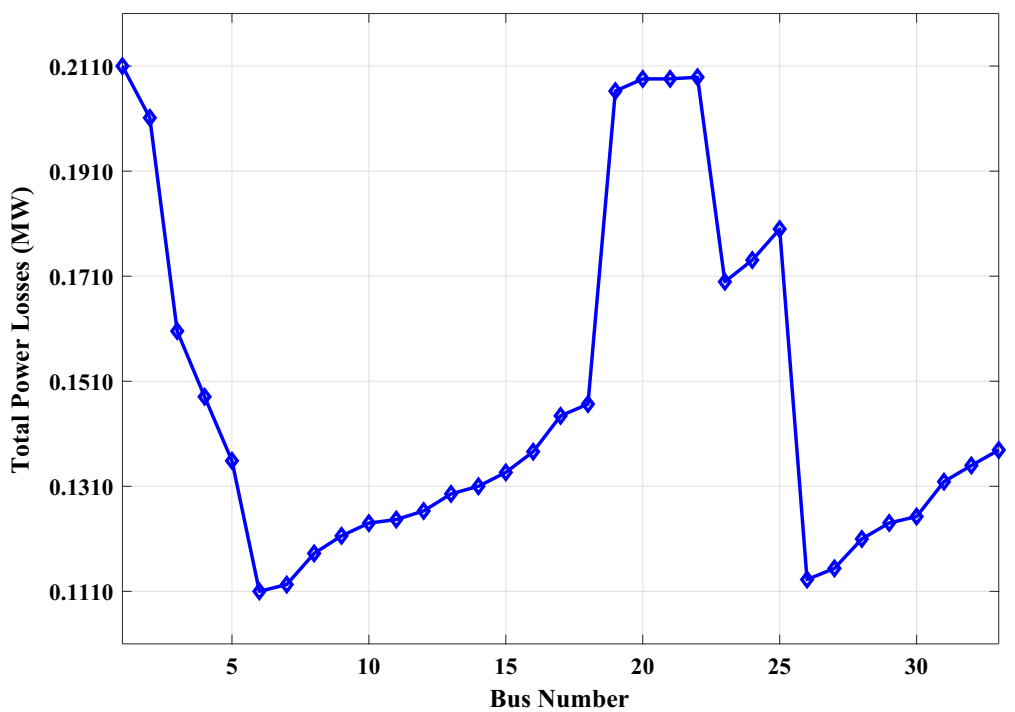

Figure 4. Optimal losses obtained with placement of optimal sized DG on individual bus: 33-bus test system.

loss has significantly reduced to $81.44 \mathrm{~kW}$ from $219.28 \mathrm{~kW}$. The results shown in Figures 3-6 clearly highlight the significance of finding optimal size and location for DG in any RDN in order to minimize power losses. The simulation results of analytical studies clearly reveals that the placement of DG at any sub-optimal location with sub-optimal sizing may increase the power losses. 


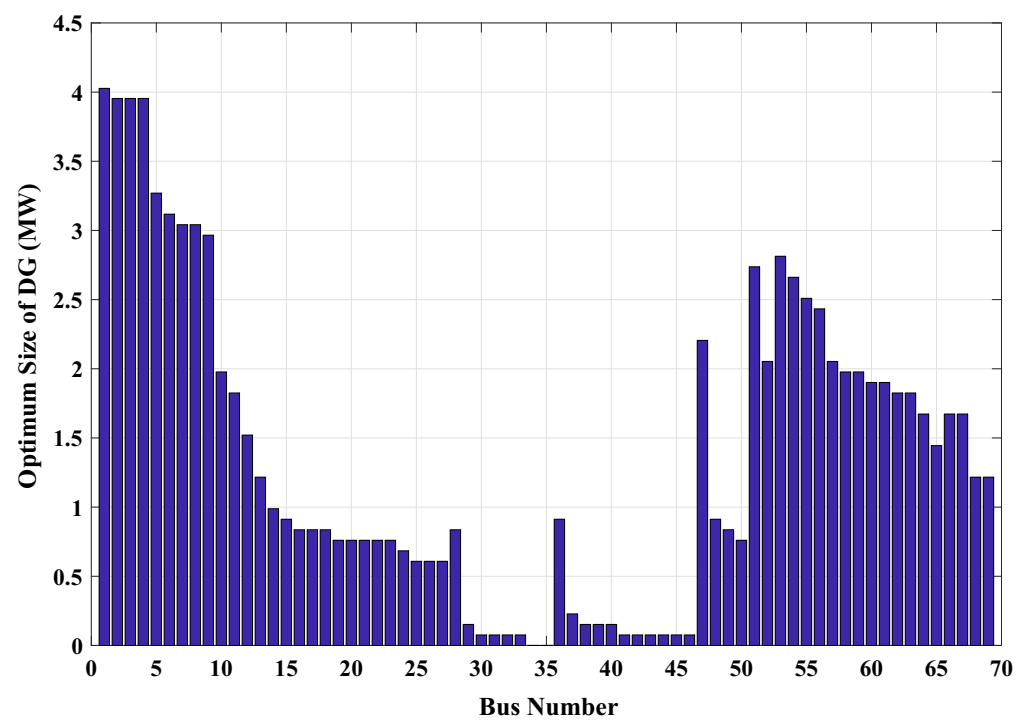

FiguRE 5. Optimal size of DG on individual bus obtained with analytical approach: 69-bus test system.

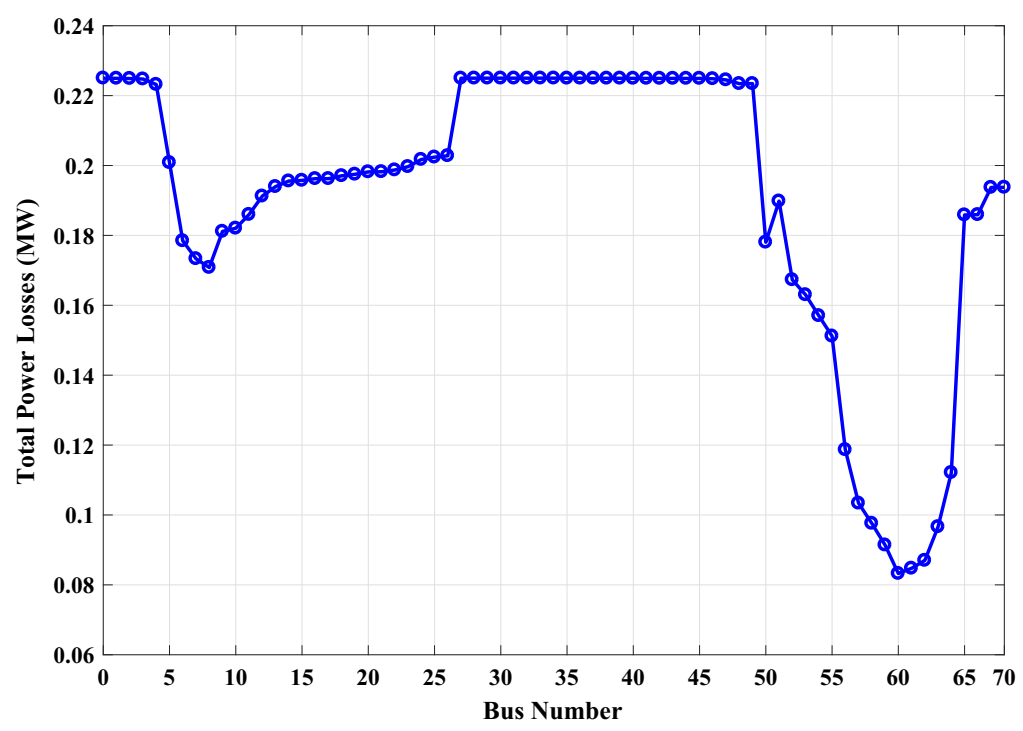

Figure 6. Optimal losses obtained with placement of optimal sized DG on individual bus: 69-bus test system.

\subsection{Optimal placement of multiple DGs (with \& without sizing constraints) using TLBO approach}

The studies presented in Section 6.1 was limited to determination of optimal size of DG at a single optimal location for a given RDN. Studies reported in $[13,26]$ have shown that the losses in the network can further be minimized with proper sizing of DG placed at more than one location. However, these studies were limited to 
TABLE 1. Simulation parameters and computational time in TLBO for single objective optimization: 33- and 69-bus test systems.

\begin{tabular}{lll}
\hline \multirow{2}{*}{ Parameters } & \multicolumn{2}{c}{ Values } \\
\cline { 2 - 3 } & 33 bus & 69 bus \\
\hline Population size & 50 & 50 \\
Number of generations & 500 & 2000 \\
Number of run & 20 & 10 \\
Computational time per run & 2.14 min & $22.19 \mathrm{~min}$ \\
\hline
\end{tabular}

TABLE 2. Decision variables and their limits in TLBO algorithm.

\begin{tabular}{lllll}
\hline \hline \multirow{2}{*}{$\begin{array}{l}\text { Decision variables } \\
\text { (DVs) }\end{array}$} & \multicolumn{2}{c}{33 -bus } & \multicolumn{2}{c}{$69-$ bus } \\
\cline { 2 - 5 } DG size (MW) & 01 & $0.70-3.72$ & 01 & $0.05-3.80$ \\
DG location (Bus No.) & 32 & $2-33$ & 68 & $2-69$ \\
\hline
\end{tabular}

finding out only 2 or 3 such locations for DGs. In order to reduce carbon footprint in environment, it is very much imperative to increase the power generation by renewable energy source, which in turn significantly increase the DG penetration in DN. Hence, an attempt is made in this work to enhance DG penetration in DN with the determination of their optimal sizes at multiple location in order to achieve minimum power losses, improved voltage profile and better load balancing. Analytical approach adopted in Section 6.1 is computationally intensive and not feasible to determine optimal size of DG at multiple locations in DN. Hence, TLBO method is utilized where the sizes of DG in MW are set as the decision variables for TLBO algorithm for minimizing power losses as a single objective function given in equation (4.9). The minimum size of DG is chosen to be $0 \mathrm{MW}$ (no DG placement) and maximum size of DG may be as high as maximum load demand of the network. In order to avoid reverse power flow in RDN, total power generation of DGs placed at multiple locations in RDN must satisfy the constraint given in equation (6.1)

$$
\sum_{i=1}^{N_{B}} P_{\mathrm{DG}, i} \leq \sum_{i=1}^{N_{B}} P_{D, i}
$$

where, $P_{\mathrm{DG}, i}$ is MW capacity of DG at $i$ th bus, $P_{D, i}$ is MW demand at $i$ th bus and $N_{B}$ are the nodes in the network. Table 1 listed the parameters used for TLBO algorithm while solving the optimization problem. Decision variables and their limits used in TLBO Algorithm are listed in Table 2.

Figure 7 shows the simulation results for the determination of optimal sizing of multiple DGs in the 33-bus test system. In this case study, constraint on minimum sizing on DG has not been considered and size of DG is allowed to vary from $0 \mathrm{MW}$ to maximum load in the test system. It is observed that the placement DGs at multiple locations in RDN has resulted in significant reduction in real power losses to $61.80 \mathrm{~kW}$ which is $45 \%$ less as compared to optimal placement of optimal sized DG at a single location in DN. Moreover, it is noted from Figure 7 that the optimal size of DG placed at multiple locations in DN for loss reduction is also reduced by great extent in range of $0.02 \mathrm{MW}$ to $0.4 \mathrm{MW}$. Similar results have also been observed for 69-bus test system as shown in Figure 8 wherein the real power losses are reduced to $68.83 \mathrm{~kW}$ from $81.44 \mathrm{~kW}$. Further, the results shown in Figures 7 and 8 reveal the fact that size of DG at few buses is very low which may not be an economical feasible solution.

Hence, the study is extended by considering limit on minimum size of DG. Depending on the system size, constraints on minimum size of DG are selected as $0.7 \mathrm{MW}$ and $0.05 \mathrm{MW}$ for 33-bus and 69-bus test system, 


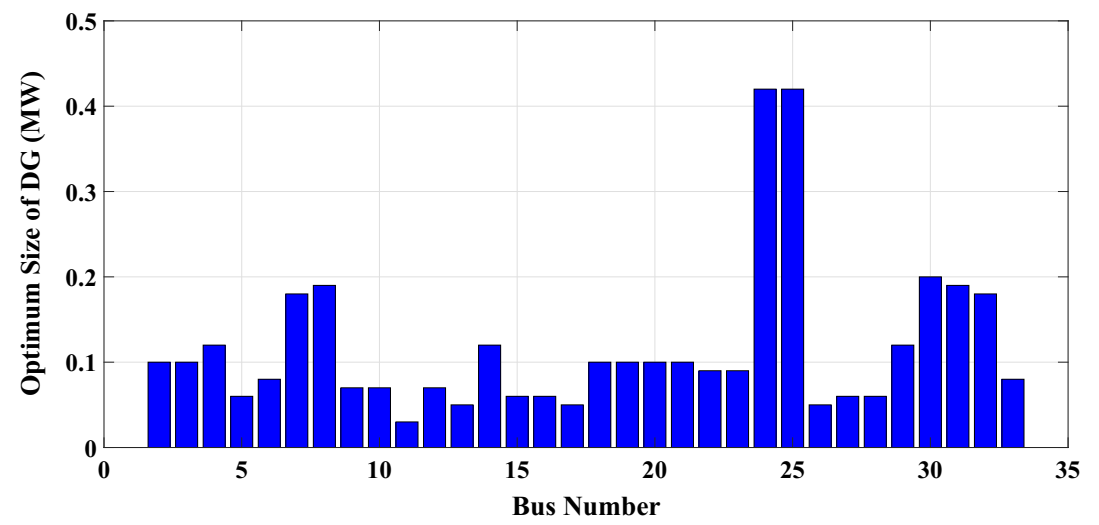

Figure 7. Optimal size of DGs at multiple locations without sizing constraints using TLBO: 33-bus test system.

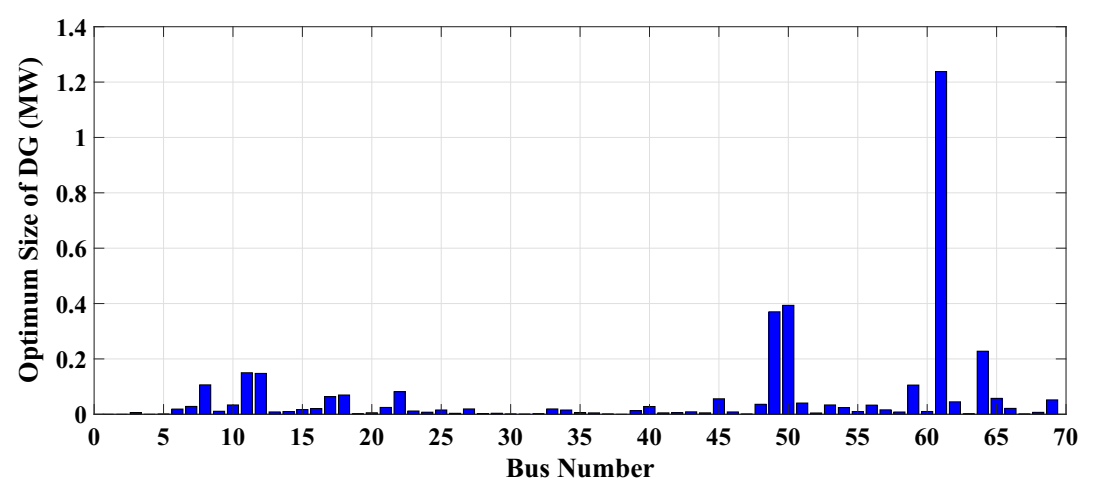

Figure 8. Optimal size of DGs at multiple locations without sizing constraints using TLBO: 69-bus test system.

respectively. The changes in DG sizing at multiple locations for reducing losses in the system after implementing DG size constraint are shown in Figures 9 and 10 for 33-bus and 69-bus, respectively, wherein candidate buses for multiple DG placement are greatly reduced. The implementation of DG sizing constraint has resulted in slight increase of $5.7 \mathrm{~kW}$ in losses for 33-bus test system whereas losses for 69 -bus test system is slight decreased by $2.36 \mathrm{~kW}$.

The performance improvement in voltage profile at different nodes in RDN has been compared for different case studies in Figures 11 and 12, for 33-bus and 69-bus test systems, respectively. It is clearly observed that the placement of DG improves voltage profile of all nodes in RDN. Also, placement of optimal sized DG at multiple locations further improve voltage profile at all nodes along with reduction in losses, which in turn improve power quality and efficiency of the network. Moreover, no significant difference on voltage profile is observed when the size of DG is constrained to minimum bound.

The comparative performance of all simulation studies carried out so far is listed in Tables 3 and 4 . Moreover, AVDI given in equation (4.11) is used to evaluate the overall impact of multiple DG placement on voltage profile. The lesser AVDI indicates more improvement in distribution network performance. It can be noticed from Tables 3 and 4 that multiple DG placement can improve AVDI by approximately $71 \%$ as compared to base case for both test systems. 


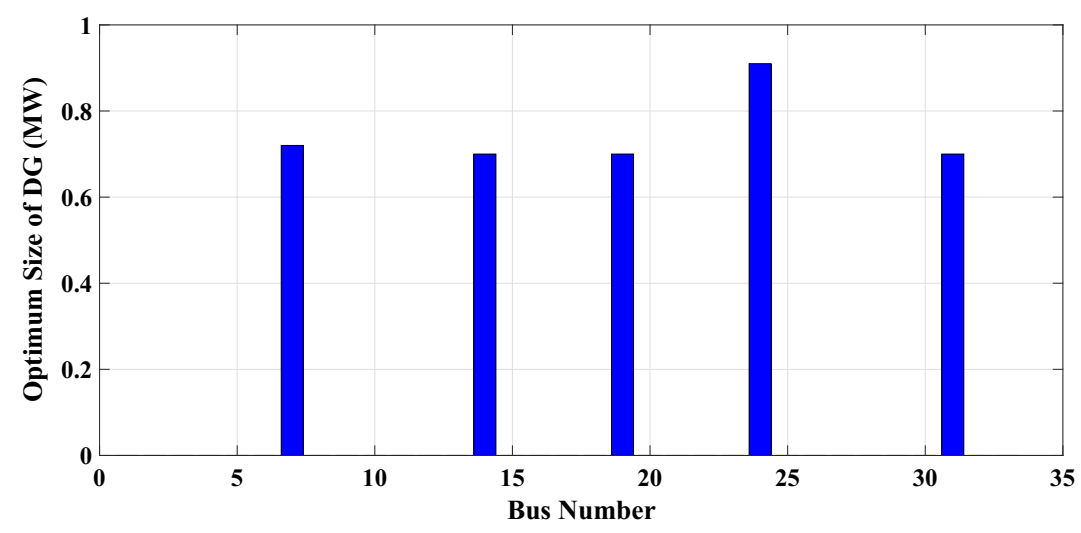

Figure 9. Optimal size of DGs at multiple locations with sizing constraints using TLBO: 33-bus test system.

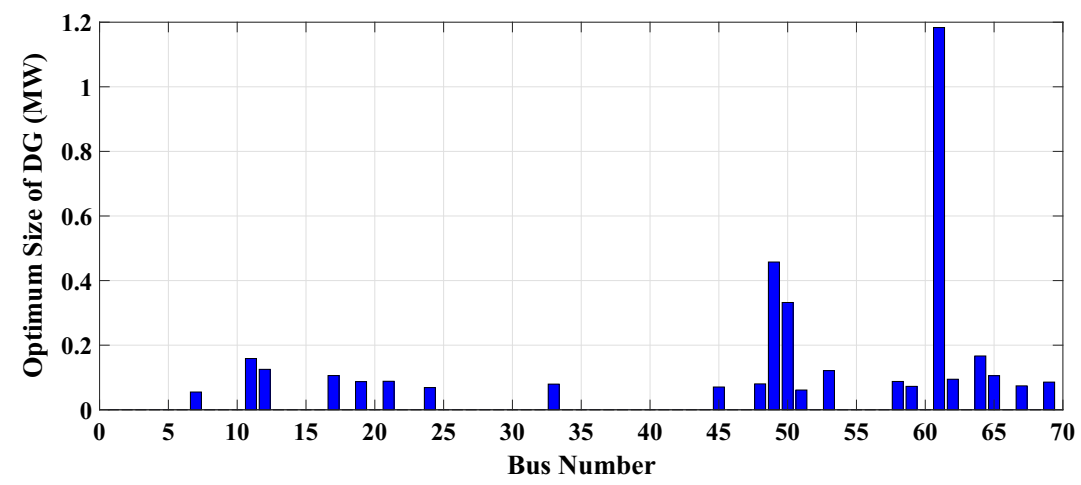

Figure 10. Optimal size of DGs at multiple locations with sizing constraints using TLBO: 69 -bus test system.

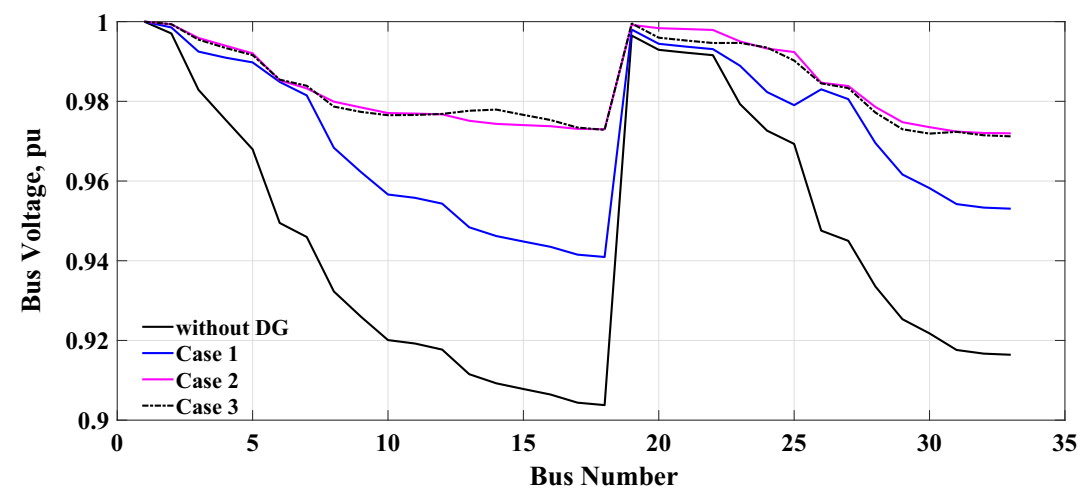

Figure 11. Voltage profile for 33-bus test system (Case 1: Analytical Approach, Case 2: TLBO approach without sizing constraints, Case 3: TLBO approach with sizing constraints). 


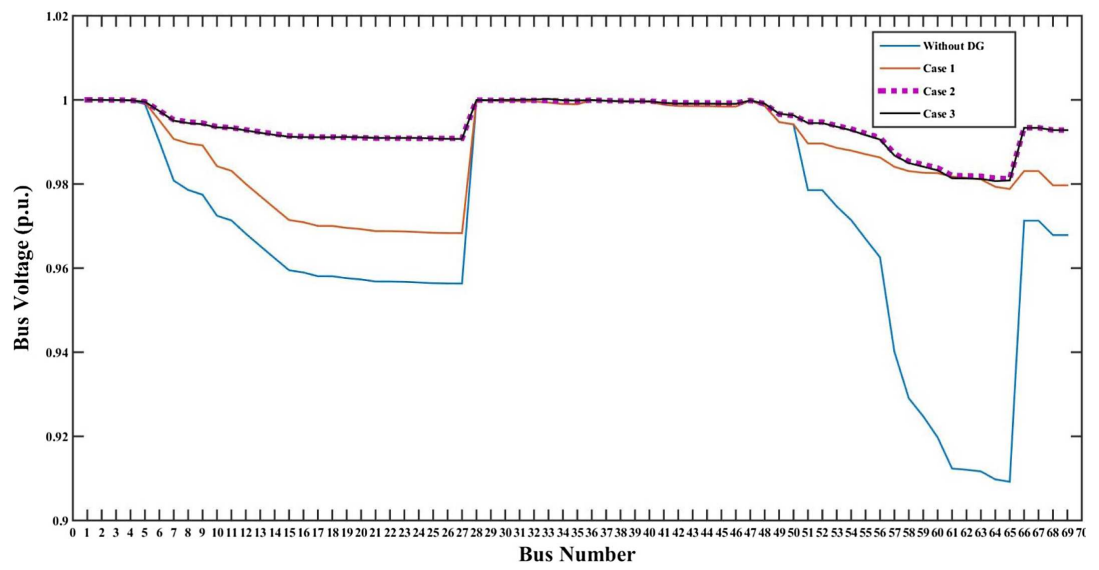

Figure 12. Voltage profile for 69-bus test system (Case 1: Analytical Approach, Case 2: TLBO approach without sizing constraints, Case 3: TLBO approach with sizing constraints).

TABLE 3. Comparative performance analysis for 33-bus test system.

\begin{tabular}{lllll}
\hline \hline Criteria & $\begin{array}{l}\text { Base case } \\
\text { without DG }\end{array}$ & $\begin{array}{l}\text { Single DG } \\
\text { placement, } \\
\text { analytical } \\
\text { approach }\end{array}$ & $\begin{array}{l}\text { Multiple DGs } \\
\text { placement } \\
\text { without sizing } \\
\text { constraints } \\
\text { using TLBO }\end{array}$ & $\begin{array}{l}\text { Multiple DGs } \\
\text { placement } \\
\text { with size con- } \\
\text { straint using } \\
\text { TLBO }\end{array}$ \\
\hline$P_{\text {Loss }}(\mathrm{KW})$ & 211.00 & 111.17 & 61.80 & 67.55 \\
$Q_{\text {Loss }}(\mathrm{KW})$ & 143.01 & 81.66 & 41.65 & 47.10 \\
AVDI $(\mathrm{pu})$ & 1.8085 & 0.9561 & 0.5318 & 0.5424 \\
\hline
\end{tabular}

TABLE 4. Comparative performance analysis for 69-bus test system.

\begin{tabular}{lllll}
\hline \hline Criteria & $\begin{array}{l}\text { Base case } \\
\text { without DG }\end{array}$ & $\begin{array}{l}\text { Single DG } \\
\text { placement, } \\
\text { analytical } \\
\text { approach }\end{array}$ & $\begin{array}{l}\text { Multiple DGs } \\
\text { placement } \\
\text { without sizing } \\
\text { constraints } \\
\text { using TLBO }\end{array}$ & $\begin{array}{l}\text { Multiple DGs } \\
\text { placement } \\
\text { with size con- } \\
\text { straint using } \\
\text { TLBO }\end{array}$ \\
\hline$P_{\text {Loss }}(\mathrm{KW})$ & 224.99 & 83.2214 & 68.8278 & 66.4776 \\
$Q_{\text {Loss }}(\mathrm{KW})$ & 102.1279 & 40.5225 & 30.3764 & 30.4318 \\
AVDI (pu) & 1.8366 & 0.8734 & 0.4045 & 0.4134 \\
\hline
\end{tabular}

\subsection{Multi-objective optimization for optimal placement of multiple DGs in 69 bus system using TLBO approach}

In distribution network, every attempt to increase DG penetration impacts on power flow distribution, realreactive power losses, voltage deviation and load balancing index. It is observed that the placement of DGs at multiple locations definitely minimize power losses, but on other hand, it pushes the node voltage beyond its upper limit. In this situation, it is a major challenge for utility operator to achieve different objectives simultaneously while keeping all constraints within their operating limit. Hence, in this work, MOO has been 
TABLE 5. Simulation parameters and computational time in TLBO for multi-objective optimization: 69-bus test system.

\begin{tabular}{llll}
\hline \hline \multirow{2}{*}{ Parameters } & \multicolumn{3}{c}{ Value } \\
\cline { 2 - 4 } & $f_{1}$ vs. $f_{2}$ & $f_{1}$ vs. $f_{3}$ & $f_{1}$ vs. $f_{2}$ vs. $f_{3}$ \\
\hline Population size & 50 & 50 & 50 \\
Number of generations & 500 & 500 & 500 \\
Computational time per run & $04 \mathrm{~min}$ & $10 \mathrm{~min}$ & $10 \mathrm{~min} 06 \mathrm{~s}$ \\
\hline
\end{tabular}

carried out which guides the utility operator to find a balanced solution among different objectives in order to improve overall performance of distribution network. Performance of 69-bus test system has been optimized with following conflicting objectives using TLBO. In all simulation studies, the sizing constraint given by equation (6.1) is imposed. Simulation parameters and computational time in TLBO for all case studies to follow are listed in Table 5.

- Power Loss $\left(f_{1}\right)$ and LBI $\left(f_{2}\right)$.

- Power Loss $\left(f_{1}\right)$ and AVDI $\left(f_{3}\right)$.

- Power Loss $\left(f_{1}\right)$, LBI $\left(f_{2}\right)$ and AVDI $\left(f_{3}\right)$.

\subsubsection{Power Loss vs. LBI}

In this case study, MOO has been carried out for achieving optimal performance of DN considering minimization of power loss $\left(f_{1}\right)$ against load balancing index $\left(f_{2}\right)$, as given in equations (4.9) and (4.10). The MOO is subjected to constraints given in equations (4.12)-(4.14) in addition to constraints in equation (6.1).

Figure 13 depicts the Pareto front obtained via solving bi-objective $\left(f_{1}\right)$ vs. $\left(f_{2}\right)$ optimization problem. Selection of any sub-optimal solution on Pareto front depends upon the priority assigned to the objectives by utility operator. The Pareto solution "A", as shown in Figure 13, indicates that the highest priority is given to minimize the objective, $\left(f_{1}\right)$ while the other objective function $\left(f_{2}\right)$ is not prioritized at all. Hence, at solution "A", the higher prioritized objective function of power loss $\left(f_{1}\right)$ optimizes to a minimum value of $67.73 \mathrm{~kW}$ and the less prioritized objective function of load balancing index $\left(f_{2}\right)$ takes a maximum value of 9.1159.

As we move along the Pareto front from solution "A" towards "B", priority assigned to objective $\left(f_{1}\right)$ decreases whereas it increases for objective $\left(f_{2}\right)$. Hence, at solution "B", objective $\left(f_{2}\right)$ is further minimized from 9.1159 to 9.0551 where as objective $\left(f_{1}\right)$ is marginally compromised from $67.73 \mathrm{~kW}$ to $68.30 \mathrm{~kW}$.

For both solutions, "A" and "B", TLBO result in different optimal sizing of DGs at multiple locations as indicated in Table 6 . In order to satisfy the priority of both objectives, utility operator may choose the solution corresponding to point "C", which lies at shortest distance from Utopia point on Pareto front. Here, solution "C" on Pareto front depicts marginal increase in power losses $\left(f_{1}\right)$ with simultaneous reduction in load balancing index $\left(f_{2}\right)$ as compared to solution "A". On the other hand, solution "C" on Pareto front results in marginal increase in load balancing index $\left(f_{2}\right)$ with simultaneous reduction in power losses $\left(f_{1}\right)$ as compared to solution "B". Comparative performance of MOO considering objectives as power loss vs. load balancing index at three solutions on Pareto front is tabulated in Table 6.

\subsubsection{Power Loss vs. AVDI}

In this case study, MOO has been carried out for achieving optimal performance of DN considering minimization of power loss $\left(f_{1}\right)$ against AVDI $\left(f_{3}\right)$, as given in equations (4.9) and (4.11). Figure 14 depicts the Pareto front obtained via solving bi-objective $\left(f_{1}\right)$ vs. $\left(f_{3}\right)$ optimization problem. As discussed previously, solution "A" on Pareto front represents higher priority to power loss minimization whereas solution " $\mathrm{B}$ " represents the higher preference to voltage deviation minimization. Utility operator may select solution "C" on Pareto front 


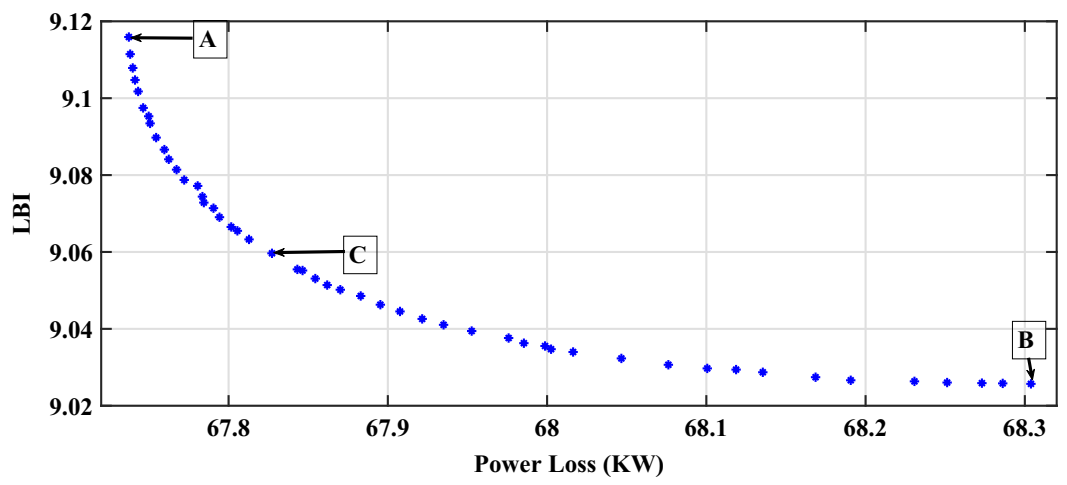

Figure 13. Pareto front for the multi-objective optimization: Power Loss vs. LBI.

TABle 6. Comparative performance of 3 different Pareto solutions: Power Loss vs. LBI.

\begin{tabular}{|c|c|c|c|c|}
\hline $\begin{array}{l}\text { Pareto } \\
\text { solution }\end{array}$ & $\begin{array}{l}\text { Power } \\
\text { loss, }\left(f_{1}\right) \\
(\mathrm{kW})\end{array}$ & LBI, $\left(f_{2}\right)$ & $\begin{array}{l}\text { Optimal DG } \\
\text { locations (Bus } \\
\text { number) }\end{array}$ & $\begin{array}{l}\text { Optimal DG size } \\
\text { (MW) }\end{array}$ \\
\hline A & 67.73 & 9.1159 & $\begin{array}{l}7,8,12,13, \\
15,25,26,28 \\
30,45,50,54 \\
57,60,62,63 \\
64,65,66\end{array}$ & $\begin{array}{lll}0.06, & 0.18, & 0.17, \\
0.05, & 0.19, & 0.06, \\
0.08, & 0.07, & 0.06, \\
0.08, & 0.65, & 0.05, \\
0.09, & 0.35, & 0.71, \\
0.28, & 0.19, & 0.09, \\
0.16 & & \end{array}$ \\
\hline B & 68.30 & 9.0256 & $\begin{array}{l}7,8,12,13, \\
15,25,26,28, \\
30,45,50,54, \\
57,60,62,64, \\
65,66\end{array}$ & $\begin{array}{lll}0.06, & 0.18, & 0.17, \\
0.06, & 0.19, & 0.06, \\
0.08, & 0.07, & 0.06, \\
0.08, & 0.65, & 0.05, \\
0.09, & 0.68, & 0.68, \\
0.19, & 0.09, & 0.14\end{array}$ \\
\hline $\mathrm{C}$ & 67.84 & 9.0551 & $\begin{array}{l}7,8,12,13, \\
15,25,26,28 \\
30,45,50,54 \\
57,60,62,63 \\
64,65,66\end{array}$ & $\begin{array}{lll}0.06, & 0.18, & 0.17, \\
0.05, & 0.19, & 0.06, \\
0.08, & 0.07, & 0.06, \\
0.08, & 0.65, & 0.05, \\
0.09, & 0.49, & 0.71, \\
0.14, & 0.19, & 0.09, \\
0.16 & & \end{array}$ \\
\hline
\end{tabular}

for balanced benefits from each objective. Comparative performance of MOO considering objectives as power loss vs. AVDI at three solutions on Pareto front is tabulated in Table 7.

\subsubsection{Power Loss vs. LBI vs. AVDI}

The results of MOO using TLBO algorithm for optimization considering all three objectives i.e. power losses $\left(f_{1}\right)$, LBI $\left(f_{2}\right)$ and AVDI $\left(f_{3}\right)$ are tabulated in Table 8 and obtained Pareto front is depicted in Figure 15.

The Pareto solution for the minimum possible value of power loss $\left(f_{1}\right)$ is $92.66 \mathrm{~kW}$, while the values of other two objective functions LBI $\left(f_{2}\right)$ and AVDI $\left(f_{3}\right)$ are 11.1850 and $0.5750 \mathrm{pu}$, respectively. Pareto solution for the minimum possible value of LBI $\left(f_{2}\right)$ is 11.1121 , while other objective functions power loss $\left(f_{1}\right)$ and AVDI $\left(f_{3}\right)$ 


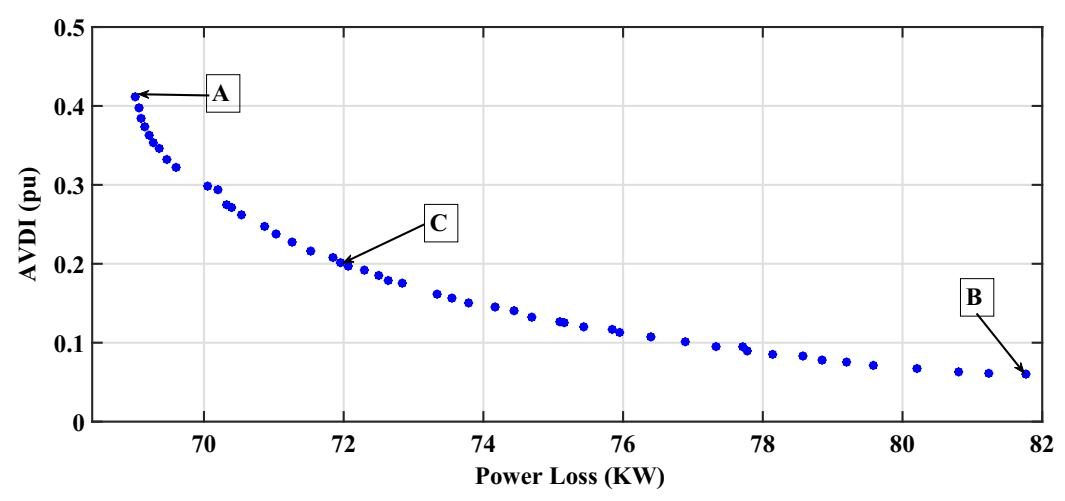

Figure 14. Pareto front for the multi-objective optimization: Power Loss vs. AVDI.

TABLE 7. Comparative performance of 3 different Pareto solutions: Power Loss vs. AVDI.

\begin{tabular}{|c|c|c|c|c|}
\hline $\begin{array}{l}\text { Pareto } \\
\text { solution }\end{array}$ & $\begin{array}{l}\text { Power } \\
\text { loss, }\left(f_{1}\right) \\
(\mathrm{kW})\end{array}$ & $\begin{array}{l}\text { AVDI, } \\
\left(f_{3}\right)(\mathrm{pu})\end{array}$ & $\begin{array}{l}\text { Optimal DG } \\
\text { locations (Bus } \\
\text { number) }\end{array}$ & $\begin{array}{l}\text { Optimal DG size } \\
(\mathrm{MW})\end{array}$ \\
\hline A & 69.01 & 0.4115 & $\begin{array}{l}9,10,12,14, \\
22,24,28,43, \\
49,51,57,59, \\
63,64\end{array}$ & $\begin{array}{lll}0.13, & 0.22, & 0.11, \\
0.13, & 0.24, & 0.05, \\
0.07, & 0.06, & 0.79, \\
0.07, & 0.20, & 0.28, \\
0.91, & 0.37 & \end{array}$ \\
\hline B & 81.76 & 0.0602 & $\begin{array}{l}9,10,12,14, \\
22,24,43,49, \\
51,57,58,59, \\
63,64,65\end{array}$ & $\begin{array}{lll}0.12, & 0.21, & 0.10, \\
0.31, & 0.24, & 0.05, \\
0.06, & 0.16, & 0.09, \\
0.22, & 0.41, & 0.27, \\
0.88, & 0.43, & 0.12\end{array}$ \\
\hline $\mathrm{C}$ & 71.95 & 0.2014 & $\begin{array}{l}9,10,12,14, \\
22,24,43,49, \\
51,57,58,59, \\
63,64\end{array}$ & $\begin{array}{lll}0.13, & 0.22, & 0.11, \\
0.32, & 0.25, & 0.05, \\
0.06, & 0.52, & 0.08, \\
0.20, & 0.11, & 0.28, \\
0.89, & 0.39, & 0.06\end{array}$ \\
\hline
\end{tabular}

are $93.41 \mathrm{~kW}$ and $0.4726 \mathrm{pu}$, respectively. Similarly, Pareto solution for the minimum possible value of AVDI $\left(f_{3}\right)$ is $0.1314 \mathrm{pu}$, while other objective functions power loss $\left(f_{1}\right)$ and LBI $\left(f_{2}\right)$ are $135.38 \mathrm{~kW}$ and 14.8986 , respectively. It is clearly observed from the simulation results that while giving priority to load balancing index improvement, there is a significant improvement in LBI from 11.1850 to 11.1121 and in AVDI from 0.5750 to $0.4726 \mathrm{pu}$. However, this benefit is achieved with marginal compromise in the power loss from 92.66 to $93.41 \mathrm{~kW}$. Thus, the Pareto front solution clearly provide the guidelines to network operator in planning and expanding the RDN considering based on the priority among various objectives.

For quantitative assessment of Pareto solutions, spread and spacing of Pareto optimal solutions are obtained. Spacing and spread indicators are used for identifying the accuracy of Pareto solutions. The spacing metric is a relative distance measure between consecutive solutions in the obtained Pareto solutions. An algorithm finding 


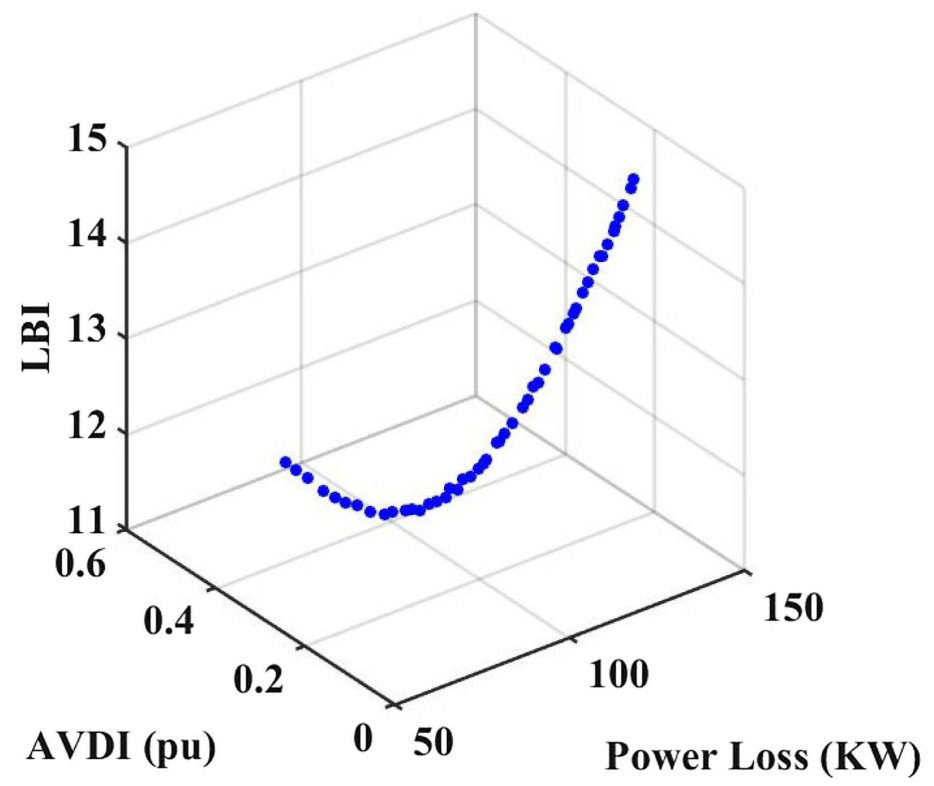

Figure 15. Pareto front for the multi-objective optimization: Power Loss vs. LBI vs. AVDI.

TABLE 8. Comparative performance of 3 different Pareto solutions: Power Loss vs. LBI vs. AVDI.

\begin{tabular}{|c|c|c|c|c|c|}
\hline $\begin{array}{l}\text { Pareto } \\
\text { solution }\end{array}$ & $\begin{array}{l}\text { Power } \\
\text { loss, }\left(f_{1}\right) \\
(\mathrm{kW})\end{array}$ & LBI, $\left(f_{2}\right)$ & $\begin{array}{l}\text { AVDI, } \\
(\mathrm{pu})\end{array}$ & $\begin{array}{l}\text { Optimal DG } \\
\text { locations (Bus } \\
\text { number) }\end{array}$ & $\begin{array}{l}\text { Optimal DG size } \\
(\mathrm{MW})\end{array}$ \\
\hline $\begin{array}{l}\operatorname{minimum} \\
f_{1}\end{array}$ & 92.66 & 11.1850 & 0.5750 & $\begin{array}{l}15,23,25,50 \\
52,65,69\end{array}$ & $\begin{array}{lll}0.45, & 0.12, & 0.05 \\
0.55, & 0.10, & 2.30 \\
0.19 & & \end{array}$ \\
\hline $\begin{array}{l}\operatorname{minimum} \\
f_{2}\end{array}$ & 93.41 & 11.1121 & 0.4726 & $\begin{array}{l}15,20,23,25 \\
50,52,65,69\end{array}$ & $\begin{array}{lll}0.30, & 0.05, & 0.09, \\
0.06, & 0.84, & 0.11, \\
1.33, & 0.20\end{array}$ \\
\hline $\begin{array}{l}\operatorname{minimum} \\
f_{3}\end{array}$ & 135.38 & 14.8986 & 0.1314 & $\begin{array}{l}15,20,23,25 \\
50,52,65,69\end{array}$ & $\begin{array}{lll}0.39, & 0.05, & 0.09 \\
0.06, & 0.85, & 0.12 \\
1.42, & 0.20\end{array}$ \\
\hline
\end{tabular}

a set of non-dominated solutions having smaller spacing is better. The spacing metric [10] is calculated using equation (6.2).

$$
S=\sqrt{\frac{1}{|P|} \sum_{i=1}^{|P|}\left(d_{i}-\bar{d}\right)^{2}}
$$

where, $P$ is the set of obtained Pareto solutions. $d_{i}$ is the distance measured between successive solutions and $\bar{d}$ is the mean value of distance measured.

Similarly, the spread metric measures the extent of spread achieved among the obtained Pareto solutions. An algorithm finding a smaller value of spread is able to find a better diverse set of non-dominated solutions. The 
TABLE 9. Spacing and spread indicators for Pareto solutions.

\begin{tabular}{llll}
\hline \hline \multirow{2}{*}{$\begin{array}{l}\text { Performance } \\
\text { indicators }\end{array}$} & \multicolumn{3}{c}{ Value } \\
\cline { 2 - 4 } & $f_{1}$ vs. $f_{2}$ & $f_{1}$ vs. $f_{3}$ & $f_{1}$ vs. $f_{2}$ vs. $f_{3}$ \\
\hline Spacing metric, $V$ & 0.00283 & 0.00318 & 0.00301 \\
Spread metric, $\Delta$ & 1.269 & 1.193 & 1.228 \\
\hline
\end{tabular}

spread metric is calculated using equation (6.3)

$$
\Delta=\frac{\sum_{m=1}^{M} d_{m}^{e}+\left|d_{i}-\bar{d}\right|}{\sum_{m=1}^{M} d_{m}^{e}+|P| \bar{d}}
$$

where, $m$ indicates the number of objectives. $d_{i}$ represents the Euclidean distances between neighboring solutions having the mean value and $d_{m}^{e}$ is the distance between extreme solutions.

Table 9 indicates the values of spacing and spread matrices. The literature review on state-of-art algorithms shows that lower values of spread and space matrices indicates better agreement of approximate and true Pareto front [10]. Values obtained for spacing \& spread matrices of the present work are inline with acceptable range.

\section{Conclusions}

Optimal sizing of DG, at a single location in RDN, satisfying single objective can easily be carried out using analytical approach. However, it consumes more computational time as the system size increases and it fails to determine multiple location of DGs in RDN. Hence, TLBO is used in this work to determine optimal sizing of DG at multiple location for 33-nodes and moderately larger 69-nodes test systems. Placement of DGs at multiple location with appropriate sizing in both test systems can successfully reduce losses up to $39 \%$ and $18 \%$ for 33-nodes and 69-nodes, respectively. Simulation studies on 69-nodes test systems reveals that an attempt to improve voltage profile through RDN marginally increases the system losses. Hence, comprehensive simulation studies have been carried out using TLBO for optimizing different conflicting objectives simultaneously in MOO framework. Different Pareto fronts are obtained considering bi-objectives as well as tri-objectives for 69-nodes test system. Each solution obtained on Pareto front has a specific priority for different objectives under consideration and represents a corresponding set of optimal DG size for a particular location in RDN. Simulation results of tri-objective optimization with a higher priority given to load balancing index results in a significant improvement both for LBI and AVDI with marginal compromise in power loss minimization. Utility operators will be benefited in taking decisions on sizing and placement of DGs at multiple locations in RDN. The operator can easily incorporate priorities of objectives while taking decisions for overall overall system performance improvement.

\section{REFERENCES}

[1] N. Acharya, P. Mahat and N. Mithulananthan, An analytical approach for DG allocation in primary distribution network. Electr. Power Energy Syst. Thailand 28 (2006) 669678.

[2] T. Ackermann, G. Andersson and L. Sder, Distributed generation: a definition. Electr. Power Syst. Res. 57 (2001) $195-204$.

[3] T.F. Agajie, A.O. Salau, E.A. Hailu and Y.A. Awoke, Power loss mitigation and voltage profile improvement with distributed generation using grid-based multi-objective harmony search algorithm. J. Electr. Electron. Eng. 13 (2020) 5-10.

[4] K. Akbari, E. Rahmani, A. Abbasi and M.-R. Askari, Optimal placement of distributed generation in radial networks considering reliability and cost indices. J. Intell. Fuzzy Syst. 30 (2016) 1077-1086.

[5] M. Anilkumar, N. Padhiyar and K. Moudgalya, Multi-criterion control of a bioprocess in fed-batch reactor using EKF based economic model predictive control. Chem. Eng. Res. Design 136 (2018) 282-294.

[6] M. Anilkumar, N. Padhiyar and K. Moudgalya, Multi-objective prioritized control of a semi-batch process with multiple feed and multiple products using economic MPC. In: 2018 Indian Control Conference (ICC) (2018) 264-269. 
[7] P. Bhatt, C. Long, B. Mehta and N. Patel, Optimal utilization of reactive power capability of renewable energy based distributed generation for improved performance of distribution network. In: Vol. 161 of Renewable Energy and Climate Change. Smart Innovation, Systems and Technologies. Springer, Singapore (2020).

[8] R.E. Brown, Electric Power Distribution Reliability, 2nd edition. CRC Press, Boca Raton (2009).

[9] S. Das, D. Das and A. Patra, Reconfiguration of distribution networks with optimal placement of distributed generations in the presence of remote voltage controlled bus. Renew. Sustainable Energy Rev. 73 (2017) 772-781.

[10] K. Deb, Multi-objective Optimization Using Evolutionary Algorithms. John Wiley \& Sons, New York (2001).

[11] M. Dehghani, Z. Montazeri and O.P. Malik, Optimal sizing and placement of capacitor banks and distributed generation in distribution systems using spring search algorithm. Int. J. Emerging Electr. Power Syst. 21 (2020) 20190217.

[12] A. El-Fergany, Study impact of various load models on DG placement and sizing using backtracking search algorithm. Appl. Soft Comput. 30 (2015) 803-811.

[13] A. El-Fergany, Multi-objective allocation of multi-type distributed generators along distribution networks using backtracking search algorithm and fuzzy expert rules. Electr. Power Compon. Syst. 44 (2016) 252-267.

[14] I.O. Elgerd, Electric Energy System Theory: An Introduction. McGraw-Hill Inc., New York (1971).

[15] A. Keane, State of the art techniques and challenges ahead for distributed generation planning and optimization. IEEE Trans. Power Syst. 28 (2013) 1493-1502.

[16] A.P. Lopes, N. Hatziargyriou, J. Mutale, P. Djapic and N. Jenkins, Integrating distributed generation into electric power systems: a review of drivers,challenges and opportunities. Electr. Power Syst. Res. 77 (2007) 1189-1203.

[17] P. Mehta, P. Bhatt and V. Pandya, Optimal selection of distributed generating units and its placement for voltage stability enhancement and energy loss minimization. Ain Shams Eng. J. 9 (2015) 187-201.

[18] K. Mistry and R. Roy, Enhancement of loading capacity of distribution system through distributed generator placement considering techno-economic benefits with load growth. Int. J. Electr. Power Energy Syst. 54 (2014) 505-515.

[19] M.H. Moradi and M. Abedini, A combination of genetic algorithm and particle swarm optimization for optimal DG location and sizing in distribution systems. Int. J. Electr. Power Energy Syst. 34 (2012) 66-74.

[20] A. Patwa, T. Thakur and S.C. Gupta, Voltage stability index based optimal sizing and placement of DG. In: IEEE Students' Conference on Engineering and Systems, SCES 2020. (2020) 9236720.

[21] Q. Qi, J. Wu and C. Long, Multi-objective operation optimization of an electrical distribution network with soft open point. Appl. Energy 208 (2017) 734-744.

[22] D. Rama Prabha, T. Jayabarathi, R. Umamageswari and S. Saranya, Optimal location and sizing of distributed generation unit using intelligent water drop algorithm. Sustainable Energy Technol. Assess. 11 (2015) 106-113.

[23] R.V. Rao and V.K. Patel, An elitist teaching learning based optimization algorithm for solving complex constrained optimization problems. Int. J. Ind. Eng. Comput. 93 (2012) 535-560.

[24] R.V. Rao, V.J. Savsani and D.P. Vakharia, Teaching learning based optimization: an optimization method for continuous non linear large scale problems. Inf. Sci. 183 (2012) 303-315.

[25] M. Sedghi and M. Aliakbar Golkar, Analysis and Comparison of Load flow methods for distribution networks considering distribution generation. Int. J. Smart Electr. Eng. 1 (2012) 27-32.

[26] S. Sultana and P.K. Roy, Multi objective quasi oppositional teaching learning based optimization for optimal location of distributed generator in radial distribution systems. Int. J. Electr. Power Energy Syst. 63 (2014) 534-545.

[27] J.-H. Teng, A direct approach for distribution system load flow solutions. IEEE Trans. Power Delivery 18 (2003) 882-887.

[28] G. Trivedi, A. Markana, P. Bhatt and V. Patel, Optimal sizing and placement of multiple distributed generators using teaching learning based optimization algorithm in radial distributed network. In: 6th International Conference On Control, Decision And Information Technologies (2019) 958-963. 